East African Medical Journal Vol. 80 No 2 February 2003

LOW DOSE INTRAVAGINAL MISOPROSTOL VERSUS INTRACERVICAL BALOON CATHETER FOR PRE-INDUCTION CERVICAL RIPENING T.O. Tabowei, MBBS, FMCOG, FWACS and V.O. Oboro, MBChB, FMCOG, FWACS, Department of Obstetrics and Gynaecology, Zonal General Hospital, Kwale, Delta State, Nigeria

Request for reprints to: Dr. V.O. Oboro, Department of Obstetrics and Gynaecology, LAUTECH College of Health Sciences, P.M.B. 4400, Osogbo, Osun State, Nigeria

\title{
LOW DOSE INTRAVAGINAL MISOPROSTOL VERSUS INTRACERVICAL BALOON CATHETER FOR PRE-INDUCTION CERVICAL RIPENING
}

\author{
T.O. TABOWEI, and V.O. OBORO
}

\begin{abstract}
Background: The efficacy and safety of low dose misoprostol as a ripening agent compared to the widely used balloon catheter in developing countries is undetermined. Objective: To compare the safety and efficacy of a low dose intravaginal misoprostol and intracervical Foley's catheter for cervical ripening.

Design: A prospective randomized controlled trial.

Setting: Zonal General Hospital, Kwale, Nigeria from June 1, 1998 to May 30, 2001. Methods: Candidates for pre-induction cervical ripening were randomized to receive either 250 mcg of intravaginal misoprostol every four hours $(n=60)$ or intracervical Foley's catheter $(n=61)$.

Main outcome measures: Failure to achieve cervical ripening within 24 hours, need for augmentation, maternal and foetal complications.

Results: Failure to achieve cervical ripening within two hours was reduced with misoprostol (Relative Risk [RR] 0.63, 95\% Confidence Interval [CI] 0.43 - 0.92). Need for oxytocin augmentation was less in the misoprostol group (RR 0.76, 95\% CI 0.64 to 0.91). No significant differences existed in rates for uterine hyperstimulation, Caesarean section, maternal and neonatal morbidity.

Conclusion: Intravaginal misoprostol in a low dose was compared to intracervical balloon catheter for pre-induction ripening of the cervix.
\end{abstract}

\section{INTRODUCTION}

Foley's cervical balloon catheter is widely used in developing countries for pre-induction cervical ripening. This is because it is much more affordable than intravaginal prostaglandins(1-3). Lately a prostaglandin E1 analogue, misoprostol, has been discovered and varying doses are being studied. Current evidence suggests that in vaginal doses of $25 \mathrm{mcg}$ three hourly or more, misoprostol is more effective than conventional methods of cervical ripening and labour induction(4).

Misoprostol may be the only affordable prostaglandin preparation for many poorly resourced countries. However, there is limitation to its widespread use which relates the issue of safety, particularly its association with uterine hyperstimulation $(4,5)$. It has been suggested that in centres where it has been used for labour induction, outcomes such as uterine rupture and perinatal and maternal deaths should be regularly audited(4). However when used as a ripening agent and in low doses (defined as $\leq 25 \mathrm{mcg}$ at 4 hourly or less frequent interval (4) the efficacy and safety as compared to the widely used balloon catheter in developing countries is undetermined. We therefore performed a randomized trial comparing the safety and efficacy between a low dose ( 25 mcg 4-hourly) intravaginal misoprostol and the intracervical placement of a Foley's balloon catheter for cervical ripening in patients with unfavourable cervix.

\section{MATERIALS AND METHODS}

This was a prospective open randomized comparative study, the main objective of which was to compare the efficacy of a low dose regime of intravaginal and intracervical Foley catheter. The protoco1 was approved by the misoprostol hospital committee on human investigation, and written informed consent was obtained from each subject before participation.

Candidates for the study were chosen from patients who required cervical ripening prior to induction of labour between June 1, 1998 and May 30, 2001 at the Zonal General Hospital, Kwale in Delta State, Nigeria. Eligible women were at term (between 37 and 42 completed weeks of pregnancy, with ultrasound confirmed dates) with a singleton foetus in the cephalic presentation and a Bishop score of $<4$. Exclusion criteria included rupture of membranes, placenta praevia, a non-reactive non-stress test, an estimated foetal weight of $>4000 \mathrm{gm}$, a prior uterine incision, parity $>4$, or a contraindication to prostaglandins.

Patients were randomly assigned to either misoprostol or catheter group by drawing the next in a series of opaque sealed envelopes that has been generated from a random number table. Those randomized to the misoprostol group 
received $25 \mathrm{mcg}$ misoprostol tablet (Cytotec, Searle Pharmaceuticals, High Wycombe, Bucks, UK) intravaginally in the posterior fornix, repeated every four hours until an adequate contraction pattern (three or more contractions in ten minutes), sufficient cervical ripening (Bishop score $>8$ or dilatation $>3 \mathrm{~cm}$ ), spontaneous rupture of membranes, or maximum of six doses was achieved. Those randomized to the catheter group had insertion of $16 \mathrm{~F}$ Foley catheter that was inflated with $50 \mathrm{ml}$ of sterile water at the level of the internal cervical os. This was left in-situ until spontaneously expelled, but not exceeding 12 hours when it was deflated and removed.

Once cervical ripening was achieved, artificial rupture of membranes was performed. Oxytocin augmentation was administered according to departmental protocol for women not entering active labour. This includes having rupture of membranes without an adequate contraction pattern; arrest of cervical dilatation defined as no cervical change for more than two hours. Intermittent foetal heart rate monitoring and uterine activity monitoring was performed on all patients. Abnormal uterine activity monitoring was classified as tachysystole if there were more than six contractions in 10 minutes for two consecutive 10-minutes periods or hypertonus if a single contraction lasted for more than two minutes. Hyperstimulation syndrome was defined as tachysystole or hypertonus associated with an abnormal foetal heart rate pattern. Two grams bolus of magnesium sulphate was administered for cases of hyperstimulation syndrome. Once in active phase of labour, routine intrapartum management was carried out under the guidance of attending doctor in charge of the labour ward.

The primary outcome was failure to achieve cervical ripening (Bishop score $\geq 8$ or dilatation $\geq 3 \mathrm{~cm}$ ) within 12 hours of pre-induction. Other outcome measures included failure to achieve vaginal delivery within 24 hours, need for oxytocin augmentation caesarian section rates, incidence of tachysystole, hypertonus, hyperstimulation syndrome, meconium presence, maternal and neonatal complications.

A sample of 120 (60 in each group) was calculated to detect a $20 \%$ difference in failure to achieve cervical ripening between groups with a power of $80 \%$, at a significant level of 0.05 . Entry characteristics of subjects in the misoprostol and catheter groups were compared using $\mathrm{X}^{2}$ and Fishers exact test for categorical variables and student's t-test for continuous variables. A two-tailed P < 0.05 was considered statistically significant. For each outcome studied, the relative risk [RR] and its $95 \%$ confidence intervals $[95 \% \mathrm{CI}]$ were calculated. Statistical anaysis were perfomed by using the SPSS for windows, Release 7.0 (Statistical Package for Social Sciences; SPSS, Inc., Chicago, IL).

\section{RESULTS}

One hundred and twenty-one candidates were recruited, of whom 60 were randomized to receive misoprostol, and 61 catheter. The demographic characteristics of the patients were similar between the two groups. There was no statistically significant difference in maternal age, weight, height, primigravidity, prior lower segment caesarean section, gestational age, or Bishop score at the time of recruitment (Table 1).
Table 1

Demographic characteristics, expressed as percentage or mean \pm standard deviation

\begin{tabular}{lccc}
\hline & $\begin{array}{c}\text { Misoprostol } \\
\mathrm{n}=60\end{array}$ & $\begin{array}{c}\text { Catheter } \\
\mathrm{n}=61\end{array}$ & P-value \\
\hline Maternal age (years) & $24.1 \pm 5.0$ & $24.4 \pm 5.3$ & 0.75 \\
Weight (Kg) & $72.0 \pm 15.0$ & $70.1 \pm 14.2$ & 0.67 \\
Height (cm) & $161.6 \pm 6.3$ & $162.0 \pm 5.9$ & 0.72 \\
Primigravid & $32(53.3)$ & $29(47.5)$ & 0.52 \\
Prior LSCS* & $8(13.3)$ & $10(16.4)$ & 0.64 \\
Gestational age (wk) & $37.7 \pm 3.1$ & $37.5 \pm 2.6$ & 0.70 \\
Initial Bishop score & $2.0 \pm 1.5$ & $2.2 \pm 1.4$ & 0.45 \\
\hline
\end{tabular}

*Lower segment Caesarean section.

Intravaginal misoprostol was more effective in producing cervical ripening and labour induction than intracervical Foley catheter (Table 2). Failure to achieve cervical ripening (Bishop score $>8$ or dilatation $>3 \mathrm{~cm}$ ) within 12 hours was reduced in the misoprostol group compared to the catheter group $(38 \%$ vs $61 \%$; Relative Risk [RR] 0.63, 95\% Confidence Interval [95\% CI] 0.43 - 0.92). A similar reduction was observed in failure to achieve ripening within 24 hours (3\% vs $18 \%$; RR $0.18,95 \% \mathrm{Cl} 0.04-0.80)$. In addition, failure to achieve spontaneous labour occurred less frequently in the misoprostol group as compared to the catheter group (58\% vs $84 \%$; RR $0.70,95 \% \mathrm{Cl} 0.55$ - 0.89). Also fewer patients in the misoprostol group required oxytocin augmentation (73\% vs 95\%; RR 0.77, 95\% CI 0.66 0.91). Although the risk of spontaneous rupture of foetal membranes was lower in the misoprostol group (12\% vs 16\%), statistical difference was not reached (RR 0.71, 95\% Cl 0.29 - 1.75).

Table 2

Comparison of outcomes of cervical ripening and labour induction. Values are given as $n(\%)$

\begin{tabular}{llll}
\hline & $\begin{array}{c}\text { Misoprostol } \\
(\mathrm{n}=60)\end{array}$ & $\begin{array}{r}\text { Catheter } \\
(\mathrm{n}=61)\end{array}$ & $\mathrm{RR}(95 \% \mathrm{CI})$ \\
\hline $\begin{array}{l}\text { Failure to achieve } \\
\text { cervical ripening }\end{array}$ & & & \\
$\quad \leq 12$ hours \\
$\begin{array}{l}\text { Failure to achieve } \\
\quad \text { cervical ripening: } \\
\leq 24 \text { hours }\end{array}$ & $23(38)$ & $37(61)$ & $0.63(0.43-0.92)$ \\
$\begin{array}{l}\text { Failure to achieve } \\
\text { spontaneous labour }\end{array}$ & $35(58)$ & $11(18)$ & $0.18(0.04-0.80)$ \\
$\begin{array}{c}\text { Need for oxytocin } \\
\text { augmentation }\end{array}$ & $44(73)$ & $51(84)$ & $0.70(0.55-0.89)$ \\
\hline
\end{tabular}

The intrapartum characteristics between the two groups were compared (Table 3). The duration of labour was reduced in the misoprostol group than in the catheter group. The mean time from initiation of 
cervical ripening until vaginal delivery was shortened in the misoprostol group $(\mathrm{p}<0.001)$. Also, among the vaginal deliveries, failure to deliver within 24 hours was reduced in the misoprostol group $27 \%(16 / 60)$ vs $48 \%$ (29/61), RR 0.56, 95\% Cl 0.34 - 0.92. No significant difference existed in the mode of delivery.

Table 3

Intrapartum and delivery characteristics

\begin{tabular}{lccc}
\hline & $\begin{array}{c}\text { Misoprostol } \\
\mathrm{n}=60\end{array}$ & $\begin{array}{c}\text { Catheter } \\
\mathrm{n}=61\end{array}$ & P-value \\
\hline $\begin{array}{l}\text { Duration of labour } \\
\text { Intervention-derivery } \\
\text { interval (hours) }\end{array}$ & $7.1 \pm 3.3$ & $10.3 \pm 3.7$ & $<0.001$ \\
$\begin{array}{l}\text { Mode of delivery* } \\
\text { Unassisted }\end{array}$ & $22.7 \pm 7.1$ & $31.3 \pm 8.0$ & $<0.001$ \\
$\begin{array}{l}\text { vaginal derivery } \\
\text { Operative }\end{array}$ & $39(65.0)$ & $36(59.0)$ & \\
$\begin{array}{l}\text { vaginal delivery } \\
\text { Caesarean section }\end{array}$ & $13(21.7)$ & $15(24.6)$ & 0.788 \\
\hline
\end{tabular}

$* X^{2}=0.477 ;$ d.f $=2$

Table 4

Complications

\begin{tabular}{|c|c|c|c|c|}
\hline & $\begin{array}{l}\text { Misoprostol } \\
(\mathrm{n}=60)\end{array}$ & $\begin{array}{l}\text { Catheter } \\
(\mathrm{n}=61)\end{array}$ & $\begin{array}{c}\text { Relative } \\
\text { risk }\end{array}$ & $\begin{array}{c}95 \% \\
\text { confidence } \\
\text { interval }\end{array}$ \\
\hline Tachysystole & $14(23)$ & $3(5)$ & 4.7 & $1.4-15.7$ \\
\hline Hypertonus & $5(8)$ & $1(2)$ & 5.1 & $0.6-42.2$ \\
\hline $\begin{array}{l}\text { Hyperstimulation } \\
\text { syndrome }\end{array}$ & $3(5)$ & $1(2)$ & 3.1 & $0.3-28.5$ \\
\hline Meconium passage & $11(18)$ & $4(7)$ & 2.8 & $0.9-8.3$ \\
\hline Febrile morbidity & $3(5)$ & $7(10)$ & 0.4 & $0.1-1.6$ \\
\hline $\begin{array}{l}\text { Apgar score }<7 \\
\text { at } 5 \mathrm{~min}\end{array}$ & $4(7)$ & $3(5)$ & 1.4 & $0.3-5.8$ \\
\hline NICU* admission & $4(7)$ & $3(5)$ & 1.4 & $0.3-5.8$ \\
\hline
\end{tabular}

* Neonatal Intensive Care Unit

Overall, complications were similar between the two groups (Table 4). However, the risk for tachysystole was significantly higher in the misoprostol group compared with the catheter group (RR 5.08; 95\% Cl $0.61-42.24)$. Although hypertonus and hyperstimulation syndrome and meconium passage were more frequent in misoprostol group, statistical significance was not reached. Intrapartum chorioamnionitis occurred in one (2\%) patient in the misoprostol group compared with three $(5 \%)$ in the catheter group (RR $0.34,95 \% \mathrm{Cl} 0.04$ - 3.17). The rate for puerperal sepsis with misoprostol was $3 \%(2 / 60)$, compared with $8 \%(5 / 61)$ for catheter (RR 0.41, 95\% CI 0.08 - 2.02). There were no significant differences in proportion of neonates with Apgar scores of $<7$ at 5 minutes, or the number of neonatal intensive care unit admissions. No neonatal death occurred in either group.

\section{DISCUSSION}

Labour is often induced at term for several foetal and maternal indications. Induction of labour before the cervix is ripe often results in prolonged labour or failed induction with attendant increased risk of operative delivery and morbidity $(5,6)$. Several studies have looked for and compared cervical ripening agents. Vaginal prostaglandin preparations have proved to be beneficial and are now the most widely used agents in developed countries (7). However, vaginal prostaglandins are expensive and unstable, require refrigerated storage, hence they are less used than intracervical balloon catheter for ripening cervix in the developing world. Misoprostol, on the other hand, is inexpensive and stable, easy to administer and may be preferred to balloon catheter in doses that are safe.

In this study we compared a low dose regimen of intravaginal misoprostol with intracervical balloon catheter as pre-induction cervical ripening agents. Intravaginal misoprostol in a dose of $25 \mathrm{mcg}$ four hourly appeared to be more effective than intracervical catheter in pre-induction ripening of the cervix. It was associated with a greater number of vaginal deliveries within 24 hours. This is remarkable considering that studies comparing prostaglandins and intracervical catheters for cervical ripening (8-10) revealed no difference in efficacy. On the other hand, other studies have demonstrated that combination of Foley balloon catheter and dinoprostone was more affective than either dinaspros tone alone (11) or misoprostol alone (12). But as demonstrated in the present study, use of low dose misoprostol alone would be preferable as it is easy to administer and cheaper.

The safety of misoprostol is a matter of concern. In this study, the incidences of tachysystole is higher in the misoprostol group but was similar to other reports $(13,14)$. However, this was not associated with significant increase in the rate of hyperstimulation syndrome, or adverse neonatal outcome. Furthermore, all cases of hyperstimulation either resolved spontaneously with maternal positioning or 2 gm bolus administration of magnesium sulphate.

The limitation of this study was that it could not be blinded because of the similar methods of cervical ripening in either groups. Although this could have introduced a bias, this investigation was designed with sufficient power to detect differences in efficacy. However, the study was not strong enough to address the issue of safety, hence we used a low dose regime in an attempt to minimize the occurrence of side-effects. 
In conclusion, the low dose of misoprostol used was more effective intracervical ballon catheter for cervical ripening. But the complications related to uterine contractions were more common. Hence more studies are needed to adress the side effects. It is however promising as a drug to use in developing countries.

\section{ACKNOWLEDGEMENTS}

We wish to thank the residents and nursing staff of the Zonal General Hospital, Kwale for their cooperation and assistance during the period of this study. We also thank Dr. O.M. Loto for assistance in the statistical analysis.

\section{REFERENCES}

1. St. Onge, R.D. and Connors, G.T. Preinduction cervical ripening: a comparison of intracervical prostaglandin E2 gel versus Foley catheter. Am. J. Obstet. Gynecol. 1995; 172: 687-690.

2. Ezimokhai, M. and Nwabineli, J.M. The use of Foley's catheter in ripening the unfavorable cervix prior to induction of labour. Brit. Obstet. Gynecol, 1980; 87:1-6.

3. Thomas, I.L., Chenoweth, J.N., Trino, G.N. and Johnson, I.R. Preparation for induction of labor of the unfavourable cervix with Foley catheter compared with vaginal prostaglandin. Aust. N. Z. J. Obstet. Gynaecol. 1986; 26: 30-35.

4. Hofmeyr, G.J., Gulmezoglu, A.M. and Alfirevic, Z. Misoprostol for induction of labour: a systematic review. Brit. J. Obstet. Gynaecol. 1999; 106: 798-803.

5. Bishop, E.H. Pelvic scoring for elective induction. Obstet. Gynecol. 1964; 24:266-268.

6. Brindley, B.A. and Sokol.R.J. Induction and augmentation of labor: Basis and methods for current practice. Obstet. Gynecol. Surv. 1988; 43: 730-743.

7. Keirse, M.J.N.C. Vaginal prostagladins for cervical ripening (revised 03 April 1992). In: Keirse M. JNC, Renfrew M.J. Neilson J.P., Crowther, C., editors.Pregnancy and Childbirth Modules of The Cochrane Pregnancy and Childbirth Database [database on disk and CDROM]. The Cochrane Collaboration; issue 2, Oxford: Update Software, 995.

8. St. Onge, R.D. and Connors, G.T. Preinduction cervical ripening: a comparison of intracervical prostaglandin E2 gel versus Foley catheter. Am J Obstel Gynecoll 1995; 172: 687-690.

9. Ezimokhai M. and Nwabineli, J.M. The use of Foleys catheter in ripening the unfavorable cervix prior to induction of labour. Brit. J. Obstet. Gynaecol. 1980; 87: 1-6.

10. Thomas, I.L., Chenoweth, J.N., Trino, G.N. and Johnson, I.R. Preparation for induction of labor of the unfavourable cervix with Foley catheter compared with vaginal prostaglandin. Aust. N. Z. J. Obstet. Gynaecol. 1986; 26: 30-35.

11. Sullivan, G.A., Benton, L.W., Roach, H., Smith, L.G., Martin.R.W. and Morrison, J.C. Combining medical and mechanical methods of cervical ripening: does it increase the likelihood of successful induction of labor? J. Reprod. Med. 1996; 41: 823-827.

12. Perry, K.G. Jr., Larmon J.E., May. W.L., Robinette, L.G. and Martin, R.W. Cervical ripening: A randomized comparison between intravaginal misoprostol and an intracervical balloon catheter combined with intravaginal dinoprostone. Am .J.Obstet.Gynecol. 1998; 179: 1333-1340.

13. Sanchez-Ramos,L., Kaunitz, A.M., Del Valle, G.O., Delke, L., Schroeder, P.A. and Briones, D.K. Labor induction with the prostaglandin El methyl analogue misoprostol versus oxytocin: a randomized trial. Obstet. Gynecol. 1993; 81:332336.

14. Wing, D.A., Jones, M.M., Rahall, A., Goodwin, T.M., Paul, R.H. A comparison of misoprostol and prostaglandin E2 gel for preinduction cervical ripening and labor induction. Am. J. Obstet. Gynecol. 1995; 172:1804-1810 